\title{
İnme Hastalarında Robot Destekli Üst Ekstremite Eğitiminin El Fonksiyonu ve Yaşam Kalitesi Üzerine Etkisi
}

The Effect of Robot-Assisted Upper Extremity Training on Hand Function and Quality of Life in Stroke Patients

'İstanbul Üniversitesi-Cerrahpașa, Sağlik Blimleri Fakültesi, Fizyoterapi ve

Rehabilitasyon Bölümü, İstanbul, Türkiye

2Sağlık Bilimleri Üniversitesi, İstanbul Fizik Tedavi ve Rehabilitasyon Eğitim ve Araștırma Hastanesi, Fizik Tedavi ve Rehabilitasyon Bölümü, İstanbul, Türkiye

${ }^{3}$ İstanbul Üniversitesi-Cerrahpaşa, Lisansüstü Eğitim Enstitüsü, Kardiyoloji Anabilim Dal,

İstanbul, Türkiye
${ }^{1}$ Rüstem Mustafaoğlu, ${ }^{2,3}$ Abdurrahim Yıldız, ${ }^{2}$ Fatma Nur Kesiktaş,

Çalışmanın amacı, inmeli hastalarda geleneksel rehabilitasyona ek olarak uygulanan robot destekli üst ekstremite eğitiminin el fonksiyonu ve yașam kalitesi üzerine etkisini araștırmaktı. Çalısmaya katılmaya gönüllü toplam 49 kronik inmeli hasta dahil edildi. Tüm hastalar geleneksel rehabilitasyon programına ek olarak günde 30 dakika, haftada 5 kez, 6 hafta boyunca ArmeoSpring üst ekstremite robotik cihazı ile eğitime katılan hastaların geçmişe yönelik bilgileri kayıt edildi. Hastaların başlangıçta ve tedavi sonunda el fonksiyonları ABILHAND İnme El Fonksiyonu anketi ve yaşam kaliteleri ise İnme Etki Ölçeği 3.0 (İEÖ) kullanılarak değerlendirildi. Çalışmaya katılan inmeli hastaların \%57,2'si kadın ve yaş ortalamaları $51,6 \pm 11,1$ yıl idi. İnmeden sonra geçen süre ortalamaları ise 3,1 $\pm 1,7$ yıl idi. Eğitimden sonra hastaların ABILHAND İnme El Fonksiyonu skorlarında istatistiksel olarak anlamlı iyileșme olduğu saptandı ( $\mathrm{p}=0,0001)$. Ayrıca, İEÖ 3.0'ın el fonksiyonu ( $\mathrm{p}=0,0001)$ ve günlük yaşam aktiviteleri $(\mathrm{p}=0,0001)$ alanları başta olmak üzere tüm alanlarda anlamlı düzeyde gelişme olduğu bulundu $(\mathrm{p}<0,05)$. Geleneksel rehabilitasyon program ile kombine edilmiş robot destekli üst ekstremite eğitiminin inmeli hastaların el fonksiyonlarını ve özellikle günlük yaşam aktivitelere katılımlarını artırarak yaşam kalitelerini iyileştirdiği görüldü.

Anahtar Kelimeler: İnme, robotik rehabilitasyon, üst ekstremite, fonksiyon, yaşam kalitesi

\section{Abstract}

The aim of the study was to investigate the effects of robot-assisted upper extremity training on hand function and quality of life in stroke patients. A total of 49 chronic stroke patients who volunteered to participate in the study were enrolled. In addition to the traditional rehabilitation program, all patients received upper extremity training with the ArmeoSpring robotic device for 30 minutes a day, 5 times a week, for 6 weeks. Hand functions of the patients at the baseline and at the end of the treatment were evaluated using the ABILHAND Stroke Hand Function Questionnaire and their quality of life using the Stroke Impact Scale 3.0 (SIP). A $57.2 \%$ of the stroke patients participating in the study were female and the mean age was $51.6 \pm 11.1$ years. The mean time after stroke was 3.1 \pm 1.7 years. A statistically significant improvement was found in the ABILHAND Stroke Hand Function Questionnaire scores of the patients after the training $(\mathrm{p}=0.0001)$. In addition, it was found that there was a significant improvement in all areas, especially hand function $(\mathrm{p}=0.0001)$ and activities of daily living $(\mathrm{p}=0.0001)$ of SIP 3.0. It was observed that robot-assisted upper extremity training combined with the traditional rehabilitation program improved the quality of life of stroke patients by increasing their hand functions and especially their participation in daily life activities.

Keywords: Stroke, robotic rehabilitation, upper limb, function, quality of life 


\section{Giriş}

İnme olarak adlandırılan serebrovasküler olay, ciddi ve yaygın bir sağlık sorunudur. Dünyada birçok ülkede ikinci veya üçüncü en yaygın ölüm nedenidir ve hayatta kalanların bağımsızlığını ve yaşam kalitesini önemli ölçüde etkilemektedir (1). Dünya genelinde her y1l yaklaşık olarak 13,7 milyon kişi inme geçirmekte, 5,5 milyon kişi bu nedenle hayatını kaybetmekte ve 5 milyon kişide inme sonrası yaşamları boyunca kalıcı motor etkilenim meydana gelmektedir (2). Ülkemizde ise 2018 y1lındaki toplam ölümlerin \%22,4'ünün serebrovasküler olaydan kaynaklandığı bildirilmiştir. Hastaların \%20'si erken dönemde olmak üzere yaklaşık \%30'u bir yıl içinde hayatını kaybettiği, hayatta kalanların üçte birinin ise günlük yaşam aktivitelerinde bağımlı hale geldiği rapor edilmiştir (3).

İnme sonras1 üst ekstremite alt ekstremiteye göre daha çok etkilenmekte olup motor iyileşme üst ekstremitede daha zayıf olmaktadır. İnmeli hastalarda tedavi ile kazanılan fonksiyonel bağımsızlık düzeyinin üst ekstremite ve el motor bozukluğu ile büyük oranda ilişkili olduğu bildirilmiştir (4). İnmeli hastaların yaklaşık \%30 ila \%66'sı kas güçsüzlüğü, spastisite, sensorimotor yetersizlikler nedeniyle üst ekstremite kalıcı fonksiyon kayıplarına bağlı olarak günlük yaşam aktivitelerinde etkilenen ekstremitelerini kullanamamaktadır bu durum hastaların yaşam kalitelerini etkilemektedir $(5$, 6). Üst ekstremite fonksiyonu ile yaşam kalitesinin direkt ilişkili olduğu, üst ekstremiteye yönelik uygulamaların yaşam kalitesinde belirgin gelişmelere neden olduğu bildirilmektedir (6). İnmeli bireylerin günlük yaşam aktivitelerini bağımsız olarak katılmaları için el motor fonksiyonlarının en uygun şekilde restore edilmesi önemlidir. Hastaların \%15'inden daha azında üst ekstremite normal motor fonksiyonunu geri kazanmaktadır (7). Günümüzde inme rehabilitasyonunda yaygın olarak uygulanan tedavi yöntemleri olarak konvansiyonel yöntemler (eklem hareket açıklığı egzersizleri, kuvvetlendirme, germe, ortezleme ve mobilizasyon yöntemleri), nörofizyolojik yaklaşımlar, motor öğrenme yöntemleri,

\begin{abstract}
proprioseptif nöromusküler fasilitasyon teknikleri, fonksiyonel elektriksel stimülasyon, transkraniyal manyetik stimülasyon ve biofeedback'i içine alan birçok yöntemler kullanılmaktadır (8).
\end{abstract}

Serebral plastisite ve motor öğrenmeyi geliştirmek amaciyla son yıllarda geleneksel tedavilere ek olarak, robot destekli tedavi, video oyun eğitimi, sanal gerçeklik gibi teknoloji temelli rehabilitasyon programları da özellikle üst ekstremite rehabilitasyonunda kullanılmaya başlanmıştır $(9,10)$. Robotik cihazların rehabilitasyonda kullanılması, etkilenmiş üst ekstremiteye yüksek yoğunluklu, bol tekrarlı, görev odaklı ve interaktif bir tedavi seçeneği sunmaktadır. Robot destekli eğitimin sahip olduğu sanal gerçeklik veya oyun sistemi katılımcıların motivasyon düzeyini ve eğitim programlarına katılımını artırmaktadır $(11,12)$. Robot destekli eğitimle hastalar eğlenirken aynı zamanda da tedavi olmaktadırlar. Bu yöntem çoğu zaman aktif katılım gerektirse de klasik tedavilerde tamamlayıc1 bir biçimde kullanılarak hastaya büyük bir fayda sağlamaktadır (13). Literatürde robot destekli eğitimin omurilik yaralanmalı hastalar (14-16) başta olmak üzere inmeli hastalarda üst ekstremite motor fonksiyonları ve günlük yaşam aktiviteleri üzerine etkilerini araştıran kısıtlı sayıda çalışma olmasına rağmen yaşam kalitesi üzerine etkisini araştıran çalışmaya rastlanmamıștır (17-20). $\mathrm{Bu}$ nedenle çalışmamızın amacı, inmeli hastalarda geleneksel rehabilitasyona ek olarak uygulanan robot destekli üst ekstremite eğitiminin el fonksiyonu ve yaşam kalitesi üzerine etkisini araştırmaktı.

\section{Gereç ve Yöntemler}

İnme tanısıyla kabul edilen ve yatılı olarak tedavi gören ve en az altı hafta üst ekstremite robotik rehabilitasyon eğitimi almış hastalar retrospektif olarak tarandı. Çalışmaya dahil edilme kriterleri, serebral kanama veya serebral enfarktüs nedeniyle yatarak rehabilitasyon almış olmak ve değerlendirme parametreleri ile ilgili verilerin mevcut olması idi. Retrospektif analiz için hasta seçim 
kriterleri aşağıdaki gibiydi; a) 18 yaş ve üzeri olma, b) en az bir y1l önce inme geçirmiş olma, c) Modifiye Ashworth Skalası'na göre spastisite skoru dirsek, el bileği ve parmak fleksör kaslarında 2 ve altında olma, d) son 6 ay içinde Botulinum toksin A enjeksiyonu yapılmamış olma ve geleneksel rehabilitasyon programına ek olarak en az en az 30 seans robot destekli üst ekstremite eğitimine katılmış olma idi. İnme dışı nörolojik hastalık nedeniye yatış yapmış olmak, Nöromüsküler Elektrik Stimülasyonu (NMES) veya fonksiyonel elektrik stimülasyonu almış olmak, değerlendirme verilerinde eksiklik olmak ve 30 seanstan daha az üst ekstremite robot destekli eğitime katılmış olmak çalışmadan dişlanma nedeni olarak belirlendi. Çalışma etik onayı Bakırköy Dr. Sadi Konuk Eğitim ve Araştırma Hastanesi Klinik Araştırmalar Etik Kurulunun 19.06.2017 tarih ve 2017-06-22 izin kararı ile alındı. Çalışma Helsinki Deklerasyonu'na uygun olarak yürütüldü.

Çalışmaya dahil edilme kriterlerine uygun olan hastalara ait cinsiyet, yaş, boy, kilo, eğitim durumu gibi kişisel bilgiler ve inme süresi, inme tipi, etkilenen taraf gibi klinik değerlendirmeler ilk seansta sorgulanarak kaydedildi. Altı haftalık tedavi programının başında ve sonunda el fonksiyonlarını değerlendirmek için ABILHAND İnme El Fonksiyonu Anketi $(21,22)$, yaşam kalitesini değerlendirmek için ise İnme Etki Ölçeği 3.0 kullanıldı $(23,24)$.

\section{ABILHAND İnme El Fonksiyonu Anketi}

Çalışmada hastaların el fonksiyonlarını sorgulamak amacıyla Penta ve arkadaşları (22) tarafından geliştirilen ABILHAND İnme El Fonksiyonu Anketi kullanıldı. Ankette hastaların beslenme, giyinme, ev isleri gibi günlük isleri gerçekleştirmede hastanın algıladığ 1 zorluk derecesi sorgulanmaktadır. Ankette yer alan tek ya da çift el ile gerçekleştirilen 56 adet görev için hastanın kendisinden son bir aya yönelik olarak imkansiz (0 puan), zor (1 puan) ve kolay ( 2 puan) şeklinde olan seçeneklerden kendisi için uygun olanı bildirmesi istendi. Yüksek puanın daha iyi el fonksiyonu anlamına gelmektedir. Anketin inme geçirmiş hastaların üst ekstremite el becerisini ölçmek üzere kullanılmasına yönelik çalışma yapılmıştır (21). Anketin henüz ülkemizde inmeli hastalar üzerinde yapılmış ve yayınlanmış güvenilirlik ve geçerlilik çalışmasına rastlanmamıştır.

\section{İnme Etki Ölçeği 3.0}

Çalışmada hastaların yaşam kaliteleri Duncan ve arkadaşları $(25,26)$ tarafindan geliştirilmiş, geçerlilik güvenilirlik çalışmaları yapılmış İnme Etki Ölçeği 3.0 ile değerlendirildi. Bu ölçek 8 alt bölüm (kuvvet, el fonksiyonu, günlük yaşam aktiviteleri, mobilite, iletişim, duygu, hafiza ve katılım) ve 59 sorudan oluşmaktadır. Her bir soru, son bir hafta içinde yaşanan zorluğun 5 puanlı skala üzerinden değerlendirilmesi ile puanlanır. Her bir bölüm için skor 0-100 arasında değişmektedir. Ayrıca 8 alt bölüme ek olarak inme sonrası iyileşme algısının 0-100 puanlık görsel analog skala (0: Hiç iyileşme yok, 100: Tam iyileşme) ile değerlendirmesini içermektedir. Ölçeğin Türk toplumundaki inmeli hastalar üzerinde güvenilirlik ve geçerlilik çalışması Hantal ve arkadaşları (24) tarafindan yapılmıştır.

\section{Uygulanan Rehabilitasyon Programı}

\section{Geleneksel rehabilitasyon programı}

Hastalar hastanede yatarak tedavi gördükleri geleneksel rehabilitasyon programında üst ekstremite fonksiyonelliğini artırmaya yönelik olarak; üst ekstremiteye yönelik ağırlık aktarma, uzanma, ağırlık taşıma, kaldırma, kaba ve ince kavrama aktiviteleri ve sik kullanılan objeleri manipule edilmesini çeşitli şekil ve büyüklükteki objeler ile çalışılarak hastaların problem yaşadığı alanlardaki sorunların çözülmesine yönelik günlük yaşam aktivitelerinde s1k kullanılan aktiviteler seçilerek üst ekstremite fonksiyonelliğinin yeniden kazanılması hedeflendi. Ayrıca üst ekstremite kaslarına yönelik germe, kuvvetlendirme ve dayanıklık egzersizleri uyguland. Tüm bu geleneksel rehabilitasyon programı günde 45 dakika, haftada 5 gün ve 6 hafta boyunca uyguland. 


\section{Robot Destekli Üst Ekstremite Ë̆itimi}

Son y1llarda görülen teknolojik gelişmelerle paralel olarak sağlık alanında da hastaların rehabilitasyon programlarına katkı sağlamaları açısından robotik cihazların kullanımı giderek yaygınlaşmıştır. $\mathrm{Bu}$ alanda yapılan çalışmalar robot destekli üst ekstremite eğitiminin inme sonrası nöral ağların organizasyona ve fonksiyonel motor becerilerin iyileşmesine olumlu katkıları olabileceğini ileri sürmektedir $(27,28)$. Literatürde geleneksel rehabilitasyon uygulamalarına kıyasla, robotik rehabilitasyonun tekrar, performansa dair geri bildirim ve motivasyon sağlaması gibi avantajları hastaların tedaviye kat1lımlarını artırdığ1 bildirilmiştir (29-31). Hastalar bilgisayar ekranında oluşturulan sanal ortam oyunları içerisinde hasta kendi elinin simülasyonunu görebilmekte ve ekrandaki objeleri omuz, dirsek ve el bileğini belirli açılarda pozisyonlarda tutarak el ile taşıma, tutma, sikma, birakma, kavrama gibi aktiviteleri gerçekleştirebilmektedir. Çalışmamızda ArmeoSpring üst ekstremite robotik cihazı kullanılarak günde 30 dakika, haftada 5 gün, 6 hafta boyunca basitten zor seviyeye doğru ilerleyen 6 farklı oyun ile üst ekstremite eğitimine katıldılar. Oyunlar ile omuz abdüksiyon-adduksiyon ve fleksiyonekstansiyonu, bilek fleksiyonu-ekstansiyonu, önkol supinasyonu-pronasyonu ve joystik kavrama ve bırakma ile el hareketleri teşvik edildi (Şekil 1).

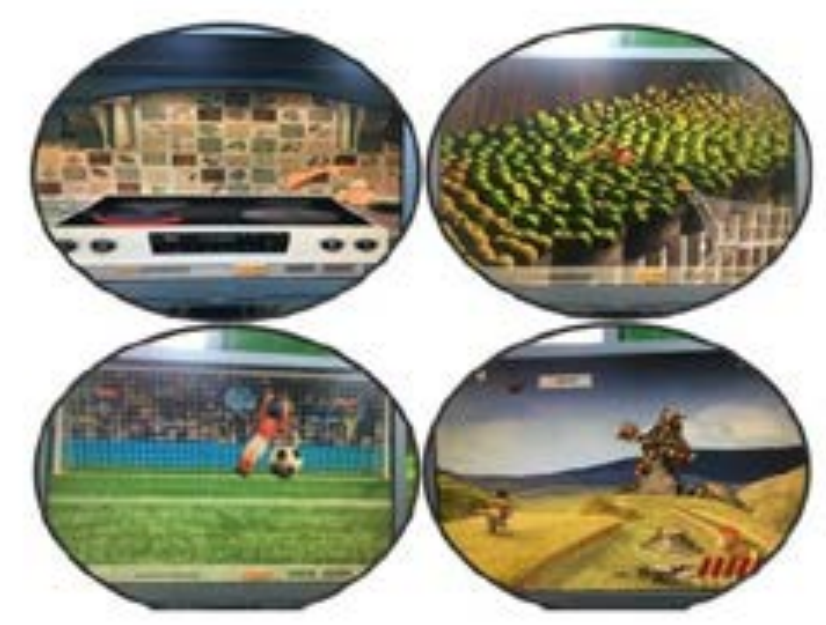

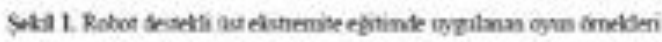

\section{Istatistiksel Analiz}

Çalışmada elde edilen verilerin analizinde "SPSS (Statistical Package for Social Sciences) (SPSS 22.0, SPSS, Chicago, IL)" istatistik programı kullanıld1, $\mathrm{p}<0,05$ (iki yönlü) olan değerler istatistiksel olarak anlamlı kabul edildi. Çalışma verilerinin normal dağıllımı gösterip göstermediğ i Shapiro-Wilk testi kullanılarak değerlendirildi. Çalışma verilerinin normal dağılıma uygun olduğu saptandı. Çalışmanın istatistiksel analizinde, değerlendirmeye alınan değişkenler en az, en çok, ortalama (Ort), standart sapma (SS) ve yüzde (\%) değerleri ile tanımlandı. Hastaların tedavi öncesi ve sonrası ABILHAND İnme El
Fonksiyonu Anketi ve İnme Etki Ölçeği 3.0 puanlarının karşılaştırılmasında Bağımlı Gruplar t-Testi kullanıldi.

\section{Bulgular}

Çalışmaya katılmaya gönüllü toplam 56 hasta dahil edilme kriterlerine göre değerlendirildi. Değerlendirilen hastalardan 5 hasta kriterlere uygun olmadığ (3 hastanın Modifiye Ashworth Skalası'na göre spastisite skoru 3 ve üzeri idi, diğer 2 hastada ise kontraktür gelişmişti), 2 hasta ise erken taburculuk nedeniyle çalışma dışı kamıştır. Çalışma 49 hasta ile tamamlanmıştır. Araştırmaya katılmış olan hastaların sosyo-demografik özellikleri incelendiğinde; çalışmaya katılan 
hastaların \%57,2'si kadın, yaş ortalamaları $51,6 \pm 11,1$ y1l ve beden kitle indeksi ortalamaları $26,1 \pm 4,4 \mathrm{~kg} / \mathrm{m} 2$ idi. Hastaların $\% 42,9$ 'u ilköğretim mezunu ve $\% 57,2$ 'si sol ekstremite etkilenimine sahipti. Hastaların etyolojisi incelendiğinde \%71,5'inin iskemik serebrovasküler olay geçirdiği görüldü.

Hastaların inmeden sonra geçen süre

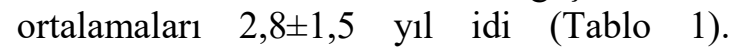

Hastaların altı haftalı geleneksel rehabilitasyona ek olarak uygulanan üst ekstremite robotik eğitim sonrası ABILHAND İnme El Fonksiyonu Anketi ve İnme Etki Ölçeği 3.0'1 değerleri eğitim öncesi ile karşılaştırıldığında, hem ABILHAND İnme El Fonksiyonu Anketi değerleri hem de İnme Etki Ölçeği 3.0'ın tüm alt boyutlarında istatistiksel olarak anlamlı gelişme olduğu saptand $1(\mathrm{p}<0,05)($ Tablo 2).

Tablo 1. Hastaların demografik ve klinik özellikleri

\begin{tabular}{|c|c|c|}
\hline & En az- En çok & $\begin{array}{c}\text { Ort } \pm \text { SS } \\
\text { veya } \\
\text { N }(\%)\end{array}$ \\
\hline \multicolumn{3}{|l|}{ Cinsiyet } \\
\hline Kadın & & $28(57.2)$ \\
\hline Erkek & & $21(42.8)$ \\
\hline Yaş (yıl) & $38-69$ & $51.6 \pm 11.1$ \\
\hline Boy $(\mathrm{cm})$ & $157-182$ & $166.5 \pm 7.5$ \\
\hline Kilo (kg) & $56-93$ & $73.8 \pm 11.3$ \\
\hline BKİ (kg/m2) & $19.25-36.68$ & $26.1 \pm 4.4$ \\
\hline \multicolumn{3}{|l|}{ Eğitim durumu } \\
\hline Okur-yazar değil & & $3(6.1)$ \\
\hline İlkokul & & $21(42.9)$ \\
\hline Ortaokul & & $12(24.5)$ \\
\hline Lise & & $9(18.4)$ \\
\hline Üniversite & & $4(8.1)$ \\
\hline \multicolumn{3}{|l|}{ Etkilenen taraf } \\
\hline Sağ & & $21(42.8)$ \\
\hline Sol & & $28(57.2)$ \\
\hline \multicolumn{3}{|l|}{ İnmenin etiyolojisi } \\
\hline İskemik & & $35(71.5)$ \\
\hline Hemorajik & & $14(28.5)$ \\
\hline Hastalık süresi (yıl) & $2-6$ & $2.8 \pm 1.5$ \\
\hline
\end{tabular}

Tablo 2. Hastaların tedavi öncesi ve sonrası ABILHAND İnme El Fonksiyonu Anketi ve İnme Etki Ölçeği 3.0 sonuçlarının karşılaştırılması

\begin{tabular}{|c|c|c|c|}
\hline & $\begin{array}{c}\text { Tedavi Öncesi } \\
\text { Ort } \pm \text { SS }\end{array}$ & $\begin{array}{l}\text { Tedavi Sonrası } \\
\text { Ort } \pm \text { SS }\end{array}$ & ${ }^{*} p$ \\
\hline $\begin{array}{l}\text { ABILHAND İnme El Fonksiyonu Anketi } \\
(0-46)\end{array}$ & $15.1 \pm 5.3$ & $27.2 \pm 5.8$ & 0.0001 \\
\hline \multicolumn{4}{|l|}{ İnme Etki Ölçeği 3.0} \\
\hline Kuvvet (4-20) & $12.7 \pm 4.5$ & $18.3 \pm 5.1$ & 0.001 \\
\hline Hafiza (7-35) & $29.9 \pm 5.6$ & $31.4 \pm 5.2$ & 0.045 \\
\hline Günlük Yaşam Aktivitesi (10-50) & $23.9 \pm 8.5$ & $37.1 \pm 9.7$ & 0.0001 \\
\hline Mobilite (9-45) & $24.1 \pm 8.2$ & $29.6 \pm 7.4$ & 0.018 \\
\hline El Fonksiyonu (5-25) & $9.8 \pm 3.9$ & $17.2 \pm 3.3$ & 0.0001 \\
\hline Sosyal Katılım (8-40) & $19.3 \pm 3.6$ & $23.1 \pm 3.9$ & 0.025 \\
\hline İyileșme (0-100) & $51.8 \pm 13.3$ & $69.3 \pm 15.1$ & 0.001 \\
\hline
\end{tabular}




\section{Tartışma ve Sonuç}

İnmeli hastalarda etkilenen beyin bölgelerinde nöroplastisitesinin yoğun, bol tekrarlı, duysal ve motor uyaranların kullanıldığı, görev odakl1 motor ve fonksiyonel becerilere yönelik uygulamaların önemi bilinmektedir $(11,12)$. Kişiye uygun motor öğrenmenin sağlanmasında kullanılan uyaranların ve geri bildirimlerin yoğunluğunun, günümüzde geliştirilmiş çeşitli teknolojilerin kullanılması ile tutarlı ve etkin bir biçimde ayarlanması mümkündür. Nörolojik hastalıklarda robotik cihazlar kinematik ölçümler ve rehabilitasyon amaçlı uygulamalar hastalarda motor iyileşmeyi kolaylaştırmak için ideal bir araç haline getiren güvenilir, kontrol edilebilir, tekrarlanabilir ve esnek bir șekilde ekstremiteleri aktif veya asistif hareketini uyarmaya olanak sağlamaktadır $(12,14,27,32)$. Üst ekstremite rehabilitasyonunda en sik kullanılan ArmeoSpring cihazın, geniş bir 3 boyutlu çalışma alanında ayarlanabilir kol ağırlığı desteği için yay mekanizmasına sahip pasif aletli bir kol ortezidir ve yardımc1 yazılımı Armeo control ile gerçek zamanlı bir cihazı olarak kullanılabilir (28,30,31). Çalışmamızda altı haftalık geleneksel rehabilitasyona ek olarak ArmeoSpring üst ekstremite robotik cihazı ile uygulanan eğitim sonrasında hastaların el fonksiyonu ve yaşam kalitesinde önemli gelişmeler olduğu görüldü.

İnme sonras1 rehabilitasyonun temel amac1, hastalığın fonksiyon kaybı üzerindeki etkisini azaltmak ve yaşam kalitesini iyileştirmek amacıyla hareket etmeyi öğrenmeyi teşvik etmektir. $\mathrm{Bu}$ nedenle, motor kontrol ve öğrenme süreçlerinde yer alan sinir yapılarını geliştirmek için fonksiyonel görevlerin tekrarlayan, yoğun ve rastgele uygulanmasının gerekli olabileceğini ileri sürmektedir (32). İnme sonras1 el fonksiyonlarının yeniden kazandırılması, hastanın fonksiyonelliğinin sağlanması açısından oldukça önemlidir. $\mathrm{Bu}$ nedenle tedavide başarıyı arttırmak ve hastayı rehabilitasyon sürecine daha fazla dahil edebilmek amacıyla yeni tedavi yöntemlerinin geliştirilmesi önem kazanmaktadır. İnmeli hastalarda robot destekli eğitim veren çalışmalar incelendiğinde, Kwakkel ve ark. (33) ve Prange ve ark. (34) çalışmalarında robot destekli üst ekstremite eğitiminin subakut ve kronik hastalarda paretik omuz ve dirsek ekleminin kısa ve uzun dönem motor kontrolünü iyileştirdiğini ancak fonksiyonel beceriler üzerinde tutarlı bir etkisi olmadığını ileri sürmüştür. Liao ve ark. (35), robot destekli üst ekstremite eğitiminin ile doz uyumlu aktif kontrol grubunu karşılaştırdıkları çalışmalarında, tüm hastalar 4 hafta boyunca haftada 5 gün, her gün 90-105 dakika süreyle eğitime alınmış. Fonksiyonel görev eğitimi ile birleştirilen simetrik ve iki taraflı robot destekli üst ekstremite eğitimi hastalarda motor fonksiyon, kol aktivitesi ve kendi kendine algilanan bilateral üst ekstremite becerilerinde önemli ölçüde iyileşme olduğunu bildirmişlerdir. Çalışma sonuçlarımıza benzer olarak ABILHAND İnme El Fonksiyonu Anketi sonuçları robot destekli üst ekstremite eğitimine katılan grupta önemli ölçüde daha fazla geliştiği rapor edilmiştir. Bir diğer çalışmada Taveggia ve ark. (17), 54 inmeli hasta üzerinde yaptıkları çalışmalarında müdahale grubu geleneksel rehabilitasyon programina ek olarak ArmeoSpring cihazı ile üst ekstremite eğitimine katılırken, kontrol grubuna ise geleneksel rehabilitasyon programina ek olarak pasif üst ekstremite mobilizasyonu uygulanmıştır. Her iki grupta günde 60 dakika, haftada 5 gün, 6 hafta boyunca eğitim almışlardır. İnme sonrası üst ekstremitede ağr1, disabilite ve spastisitenin tedavisinde robot destekli üst ekstremite eğitiminin etkili olduğunu rapor etmişlerdir. Chan ve ark. (36), çalışmalarında hafif, orta ve şiddetli üst ekstremite etkilenimi olan subakut 48 inmeli hastaya geleneksel rehabilitasyona ek olarak, günde 45 dakika, haftada 5 gün, 3 hafta süreyle ArmeoSpring ile üst ekstremite eğitimine dahil etmişlerdir. Yazarlar, robot destekli üst ekstremite eğitimin, özellikle omuz fleksiyonu gibi dikey kontrolü iyileştirmek için orta ila şiddetli üst ekstremite etkilenimi olan subakut inmeli hastalar için yararlı bir uygulama olduğu ve üst ekstremite kas tonusunda herhangi bir yan etkiye neden 
olmadığını bildirmişlerdir. Çalışmamızdan elde edilen sonuçlar da literatürle uyumlu olarak geleneksel rehabilitasyon programina ek olarak uygulanan robot destekli üst ekstremite eğitiminin inmeli hastalarda üst ekstremite fonksiyonlarında daha fazla gelişmeye katkı sağladığı görüşünü desteklemektedir. Çalışmalarda robot destekli üst ekstremite eğitiminin seans sayısı ve süresi farkl1lık göstermesine rağmen genellikle geleneksel rehabilitasyona ek olarak uygulandığı görülmektedir. Bu da bu eğitimin tek başına uygulanabilir bir eğitim şekli olmadığı diğer tedavilere ek olarak uygulanabilecek alternatif bir yaklaşım olduğunu göstermektedir. S1kl1kla robot destekli eğitimin diğer etkili rehabilitasyon yöntemleriyle kombine edilerek tedavinin etkilerinin artırılmasını önerilmektedir (37).

Üst ekstremite etkilenimi, inme sonras1 en s1k görülen ve kalıcı bozukluklardan biridir. Üst ekstremitede motor kontrolün kaybı sıklıkla günlük yaşam aktivitelerini ve yaşam kalitesini olumsuz yönde etkilemektedir. İnme sonrası elin fonksiyonel iyileşmesini sağlamak özellikle de ince motor becerilerini kazandırmak çok zordur. Günümüzde mevcut kanttlar, robot destekli eğitimin inmeli hastalarda üst ekstremite motor kontrolü ve günlük yaşam aktivitesi performansına fayda sağladığını belirtirken (38), yaşam kalitesi üzerine etkisi konusunda kanıtı yetersizdir (39). Hastaların üst ekstremiteleri tamamen iyileşmiş olsa da el becerilerinde uyumlu bir iyileşme olmadığı sürece yaşam kalitesinde anlamlı bir gelişme sağlanamayacaktır. Son yıllarda sıklıkla inmeli hastalarının sağlıkla ilişkili yaşam kalitesi araştırılmaya başlanmıştır. $\mathrm{Bu}$ nedenle inme hastalarının yaşam kalitesi değerlendirmesi fiziksel (motor yetersizlik, spastisite, ataksi, ağn, uyku bozuklukları, yorgunluk vb.) ve sosyal (iş, sosyal iletișim) boyutlarını içermesi gerekir (40). El fonksiyonları, İnme Etki Ölçeği 3.0'ın alt grupları arasında en çok etkilenen alt gruptur. Geçirilmiş inme sonrası tedavi almadan hastaların \%85'inde üst ekstremitede fonksiynel yetersizlikler görülürken, ilerleyen aylarda bu oran \%55-75'e doğru gerilemekte, \%23-43'ünde yetersiz fonksiyonel iyileşme ve yalnızca $\% 5$ hastada tam düzelme görülmektedir $(40,41)$. İnme sonrası dönemde yaşam kalitesini etkileyen faktörleri araştıran çalışmaların sonuçları ile uyumlu olarak İnme Etki Ölçeği 3.0 için hastaların yaşam kalitelerinin motor gelişim ve fonksiyonellik düzeyi arttıkça olumlu yönde gelişme gösterdiği belirtilmiştir (42). Literatürde robot destekli üst ekstremite eğitiminin inmeli hastaların yaşam kalitesi üerine etkisini araştıran çalışma sayısı oldukça kısıtlıdır (11, 43-45). Wu ve ark.(43), 42 inmeli hastaya fizyoterapist temelli, robot destekli eğitim temelli ve kontrol olmak üzer günde 90-105 dakika, haftada 5 gün 4 hafta boyunca bilateral üst ekstremite eğitimi verdikleri çalışma sonuçlarına göre kontrol ile karşılaştırıldığında fizyoterapist ve robot temelli eğitimlerin değerlendirme sonuç ölçütleri üzerinde farklı etkiler gösterdiğini bildirmişlerdir. Fizyoterapist temelli bilateral üst ekstremite eğitiminin distal üst ekstremitenin zamansal etkinliğini, düzgünlüğünü, gövde kontrolünü ve motor bozukluğunu iyileştirdiği, robot destekli eğitimin ise inmeli hastaların omuz fleksiyonunu ve yaşam kalitesini iyileştirdiğini rapor etmişlerdir. Yazarlara göre robot destekli üst ekstremite eğitimin aktif normal eklem hareket açıklığını arttırarak ve muhtemelen el bileği ve önkol spastisitesini azaltarak günlük yaşamda iyileştirilmiş fiziksel koşulların (algılanan kas gücü ve eklem hareket açıklığında artış vb.) yaşam kalitesinin fiziksel işlev alanının ve genel yaşam kalitesinin daha iyi algılanmasına yol açabileceğinden kaynaklandığını ileri sürmektedirler. Bir diğer çalışmada Lee ve ark. (11) 39 kronik inmeli hastayı NMES veya sham stimülasyon ile kombine robot destekli üst ekstremite eğitimi gruplarına ayırdığ çalışmalarında, katılımcılara 4 hafta boyunca günde 90-100 dakika ve haftada 5 gün eğitime dahil etmişler. Robot destekli eğitimle kombine olarak uygulanan sham grubu ile karşılaştırıldığında, NMES grubunda bilek fleksörlerinin modifiye Ashworth ölçeği skorunda, Wolf Motor Fonksiyon Testi hareket kalitesinde ve İnme Etki Ölçeği 3.0'ün el fonksiyonu alanında daha fazla gelişme olduğunu bildirmişlerdir. Yazarlar hastaların yaşam kalitelerindeki artışın el bileği fleksörlerinin spastisitesindeki azalmadan ve paretik eli kullanmadaki başarının öz-yeterliliği artırmasındaki 
motivasyondan

fonksiyonlarındaki

kaynaklanarak

iyileşmeden kaynaklandığını ileri sürmüşlerdir. Zengin Metli ve ark. (45), subakut inmeli hastalar üzerinde yaptıkları çalışmalarında bir gruba geleneksel rehabilitasyona ek olarak günde 30 dakika haftada 5 gün 3 hafta robot destekli üst ekstremite eğitimi verirken kontrol grubuna ise aynı süre boyunca geleneksel rehabilitasyon uygulanmıştır. Kontrol grubuyla karşılaştırıldığında robot destekli eğitim alan bireylerde SF-36'nın fiziksel alt boyutunda anlamlı gelişme görülürken, mental alt boyutunda ise kontrol grubunda daha iyi sonuçlar elde edildiği görülmüştür. Yazarlar geleneksel rehabilitasyon programina ek olarak uygulanan robot destekli üst ekstremite eğitimin, subakut inmeli hastalarda motor iyileşmeyi ve yaşam kalitesini iyileştirmede etkili olduğunu bildirmişlerdir. Çalışmamızda da literatürdeki çalışmalara benzer olarak geleneksel tedaviye ek olarak uygulanan robot destekli üst ekstremite eğitiminin yaşam kalitesinde önemli gelişmelere katkı sağladığ1 görülmüştür. Çalışmamızda inmeli hastaların yaşam kalitesini değerlendirmek için kullanılan İnme Etki Ölçeği 3.0'ın özelikle el fonksiyonu ve günlük yaşam aktiviteleri alt boyutları önemli gelişmelerin yanı sıra tüm alt boyutlarında anlamlı gelişmeler olduğu görülmektedir. Çalışmamızda inmeli hastaların üst ekstremite motor gelişimlerini ve spastisite durumlar1 değerlendirilmediğinden el fonksiyonlarındaki gelişmelerin uygulanan eğitim programının günlük yaşam aktivitelerine benzer

\section{KAYNAKLAR}

1. Langhorne P, Bernhardt J, Kwakkel G. Stroke rehabilitation. The Lancet. 2011;377:1693-1702.

2. Johnson CO, Nguyen M, Roth GA, et al. Global, regional, and national burden of stroke, 19902016: a systematic analysis for the Global Burden of Disease Study 2016. The Lancet Neurology 2019;18:439-58.

3. Kablan Y. İnme: Epidemiyoloji ve Risk Faktörleri. Türkiye Klinikleri Nöroloji-Özel Konular. 2018;11:1-19.

4. Sveen U, Bautz-Holter E, Margrethe Sodring K, et al. Association between impairments, self-care ability and social activities 1 year after stroke. Disabil rehabil. 1999;21:372-77. aktivitelerden seçilmiş olmasından ve paretik eli kullanma motivasyonundan kaynaklandığını düşünmekteyiz.

Çalışmanın bazı kısıtlılıkları mevcuttur. Birinci kısıtlılık, tüm hastalarda başlangıç değerlendirme parametrelerine göre anlaml iyileşme görülmesine rağmen, çalışmanın kontrol grubunun olmamasıdır. İkincisi, retrospektif olarak planlanmış olması ve çalışmaya iyi fonksiyonlu üst ekstremiteye sahip (Modifiye Ashworth Skalası'na göre $\leq 2)$ inme hastalarının dahil edilmesidir. Tüm bunlara bağlı olarak, mevcut çalışmanın sonuçları tüm inme hastalarına genellemeye olanak sağlamamaktadır.

Geleneksel rehabilitasyon programı ile kombine edilmiş robot destekli üst ekstremite eğitiminin inmeli hastaların el fonksiyonlarını ve özellikle günlük yaşam aktivitelere katılımlarını önemli ölçüde artırarak yaşam kalitelerini iyileștirdiği görüldü. Robot destekli üst ekstremite eğitimi, katılımcıların etkilenmiş olan üst ekstremitelerini günlük yaşam aktivitelerini iyileştirmede daha fazla kullanmaya motive etmeye katkıda bulunmaktadır. $\mathrm{Bu}$ eğitim yönteminin inme sonras1 hastaların üst ekstremite rehabilitasyonunda etkili ve eğlenceli ek bir tedavi yöntemi olarak kullanılabileceği düşüncesindeyiz. Literatürde robot destekli üst ekstremite eğitim protokollerinin farkl11ık gösterdiği görülmektedir, gelecekteki çalışmaların bu eğitim protokolünün optimum yoğunluğunun belirlemesine yönelik olması önem arz etmektedir.
5. Hendricks HT, Van Limbeek J, Geurts AC,et al. Motor recovery after stroke: a systematic review of the literature. Arch Phys Med Rehabil. 2002;83:1629-37.

6. Hakkennes S, Keating JL. Constraint-induced movement therapy following stroke: a systematic review of randomised controlled trials. Aust J Physiother 2005;51:221-31.

7. Van der Lee JH, Wagenaar RC, Lankhorst GJ, et al. Forced use of the upper extremity in chronic stroke patients: results from a single-blind randomized clinical trial.Stroke. 1999;30:2369-75.

8. Özer İŞ, Sorgun MH, Rzayev S, et al. Genç iskemik inme hastalarında inme etiyolojisi, risk 
faktörleri ve hastaların izlemdeki fonksiyonel durumlar1. Turk J Neurol. 2015;21:159-64.

9. Park S-W, Butler AJ, Cavalheiro V, et al. Changes in serial optical topography and TMS during task performance after constraint-induced movement therapy in stroke: a case study. Neurorehabil Neural Repair. 2004;18:95-105.

10. Kim YH, Park JW, Ko MH, et al. Plastic changes of motor network after constraint-induced movement therapy. Yonsei Med J. 2004;45:24146.

11. Lee YY, Lin $\mathrm{KC}$, Cheng HJ,et al. Effects of combining robot-assisted therapy with neuromuscular electrical stimulation on motor impairment, motor and daily function, and quality of life in patients with chronic stroke: a doubleblinded randomized controlled trial. $J$ Neuroeng Rehabil. 2015;12:96.

12. Taveggia G, Borboni A, Salvi L, et al. Efficacy of robot-assisted rehabilitation for the functional recovery of the upper limb in post-stroke patients: a randomized controlled study. Eur J Phys Rehabil Med. 2016;52:767-73.

13. Lanningham-Foster L, Foster RC, McCrady SK,et al. Activity-promoting video games and increased energy expenditure. J Pediatr. 2009;154:819-23.

14. Francisco GE, Yozbatiran N, Berliner J, et al. Robot-assisted training of arm and hand movement shows functional improvements for incomplete cervical spinal cord injury. Am J Phys Med Rehabil. 2017;96:171-77.

15. Zariffa J, Kapadia N, Kramer J, et al. Feasibility and efficacy of upper limb robotic rehabilitation in a subacute cervical spinal cord injury population. Spinal Cord. 2012;50:220-26.

16. Singh H, Unger J, Zariffa J,et al. Robot-assisted upper extremity rehabilitation for cervical spinal cord injuries: a systematic scoping review. Disabil Rehabil Assist Technol. 2018;13:704-15.

17. Taveggia G, Borboni A, Salvi L, et al. Efficacy of robot-assisted rehabilitation for the functional recovery of the upper limb in post-stroke patients: a randomized controlled study. Eur J Phys Rehabil Med. 2016;52:767-73.

18. Veerbeek JM, Langbroek-Amersfoort AC, van Wegen EE, et al. Effects of Robot-Assisted Therapy for the Upper Limb After Stroke. Neurorehabil Neural Repair. 2017;31:107-21.

19. Lee MJ, Lee JH, Lee SM. Effects of robot-assisted therapy on upper extremity function and activities of daily living in hemiplegic patients: A singleblinded, randomized, controlled trial. Technol Health Care. 2018;26:659-66.

20. Rodgers H, Bosomworth H, Krebs HI, et al. Robot assisted training for the upper limb after stroke (RATULS): a multicentre randomised controlled trial. Lancet. 2019;394:51-62.

21. Penta M, Tesio L, Arnould $\mathrm{C}$, et al. The ABILHAND questionnaire as a measure of manual ability in chronic stroke patients: Raschbased validation and relationship to upper limb impairment. Stroke. 2001;32:1627-34.

22. Penta M, Thonnard JL, Tesio L. ABILHAND: a Rasch-built measure of manual ability. Arch Phys Med Rehabil. 1998;79:1038-42.
23. Vellone E, Savini S, Fida R, et al. Psychometric evaluation of the Stroke Impact Scale 3.0. J Cardiovasc Nurs.2015;30:229-41.

24. Hantal AO, Dogu B, Buyukavci R, et al. Stroke impact scale version 3.0: study of reliability and validity in stroke patients in the turkish population. Turk $J$ Phys Med Rehabil.2014;60:106-17.

25. Duncan PW, Wallace D, Lai SM, et al. The Stroke Impact Scale version 2.0: evaluation of reliability, validity, and sensitivity to change. Stroke. 1999;30:2131-40.

26. Lai SM, Studenski S, Duncan PW, et al. Persisting consequences of stroke measured by the Stroke Impact Scale. Stroke. 2002;33:1840-44.

27. You SH, Jang SH, Kim YH, et al. Virtual realityinduced cortical reorganization and associated locomotor recovery in chronic stroke: an experimenter-blind randomized study. Stroke. 2005;36:1166-71.

28. Colomer C, Baldoví A, Torromé S, et al. Efficacy of Armeo ${ }^{\circledR}$ Spring during the chronic phase of stroke. Study in mild to moderate cases of hemiparesis. Neurologia. 2013;28:261-67.

29. Dixit S, Tedla JS. Effectiveness of robotics in improving upper extremity functions among people with neurological dysfunction: a systematic review. Int J Neurosci. 2019;129:369-83.

30. Bustamante Valles K, Montes S, Madrigal Mde J, et al. Technology-assisted stroke rehabilitation in Mexico: a pilot randomized trial comparing traditional therapy to circuit training in a Robot/technology-assisted therapy gym. $J$ Neuroeng Rehabil. 2016;13:83.

31. Babaiasl M, Mahdioun SH, Jaryani P, Yazdani M. A review of technological and clinical aspects of robot-aided rehabilitation of upper-extremity after stroke. Disabil Rehabil Assist Technol. 2016;11:263-80

32. Burgar CG, Lum PS, Shor PC,et al. Development of robots for rehabilitation therapy: The Palo Alto VA/Stanford experience. $J$ Rehabil Res Dev. 2000;37:663-74.

33. Kwakkel G, van Peppen R, Wagenaar RC, et al. Effects of augmented exercise therapy time after stroke: a meta-analysis. Stroke. 2004;35:2529-39.

34. Prange G, Jannink M, Groothuis-Oudshoorn C, et al. Systematic review of the effect of robot-aided therapy on recovery of the hemiparetic arm after stroke. J Rehabil Res Dev. 2009;43:171-84.

35. Liao WW, Wu CY, Hsieh YW, et al.Effects of robot-assisted upper limb rehabilitation on daily function and real-world arm activity in patients with chronic stroke: a randomized controlled trial. Clin Rehabil. 2012;26:111-20.

36. Chan IH, Fong KN, Chan DY, et al. Effects of arm weight support training to promote recovery of upper limb function for subacute patients after stroke with different levels of arm impairments. Biomed Res Int. 2016;2016:9346374.

37. Reinkensmeyer DJ, Boninger ML. Technologies and combination therapies for enhancing movement training for people with a disability. $J$ Neuroeng Rehabil. 2012;9:1-10.

38. Mehrholz J, Hädrich A, Platz $T$, et al. Electromechanical and robot-assisted arm training for improving generic activities of daily living, 
arm function, and arm muscle strength after stroke.Cochrane Database Syst Rev. 2012;13:CD006876.

39. Pulman J, Buckley E. Assessing the efficacy of different upper limb hemiparesis interventions on improving health-related quality of life in stroke patients: a systematic review. Top Stroke Rehabil. 2013;20:171-88.

40. Carod-Artal FJ, Trizotto DS, Coral LF,et al. Determinants of quality of life in Brazilian stroke survivors. J Neurol Sci. 2009;284:63-8.

41. Pehlivan YS, Armağan O. Elektromiyografik biofeedback ile kombine edilen elektrik stimulasyon ve egzersiz uygulamalarının inme sonras1 üst ekstremite rehabilitasyonuna etkisi. Turk J Phys Med Rehabil. 2011;57:66-72.

42. Aström M, Asplund K, Aström T. Psychosocial function and life satisfaction after stroke. Stroke. 1992;23:527-31.

43. Wu CY, Yang CL, Chuang LL, et al. Effect of therapist-based versus robot-assisted bilateral arm training on motor control, functional performance, and quality of life after chronic stroke: a clinical trial. Phys Ther. 2012;92:1006-16.

44. Timmermans AA, Lemmens RJ, Monfrance M, et al. Effects of task-oriented robot training on arm function, activity, and quality of life in chronic stroke patients: a randomized controlled trial. $J$ Neuroeng Rehabil. 2014;11:45.

45. Zengin-Metli D, Özbudak-Demir S, Eraktaș İ,et al. Effects of robot assistive upper extremity rehabilitation on motor and cognitive recovery, the quality of life, and activities of daily living in stroke patients. J Back Musculoskelet Rehabil. 2018;31:1059-64.

@Copyright 2021 by Osmangazi Tıp Dergisi - Available online at tip.ogu.edu.tr @Telif Hakkı 2021 ESOGÜ Tıp Fakültesi - Makale metnine dergipark.org.tr/otd web sayfasından ulaşılabilir. 